\title{
REDUCTION OF PANTOGRAPH INFLUENCE ON ENERGY CONSUMPTION
}

\author{
Karel Raz, Martin Zahalka \& Zdenek Chval
}
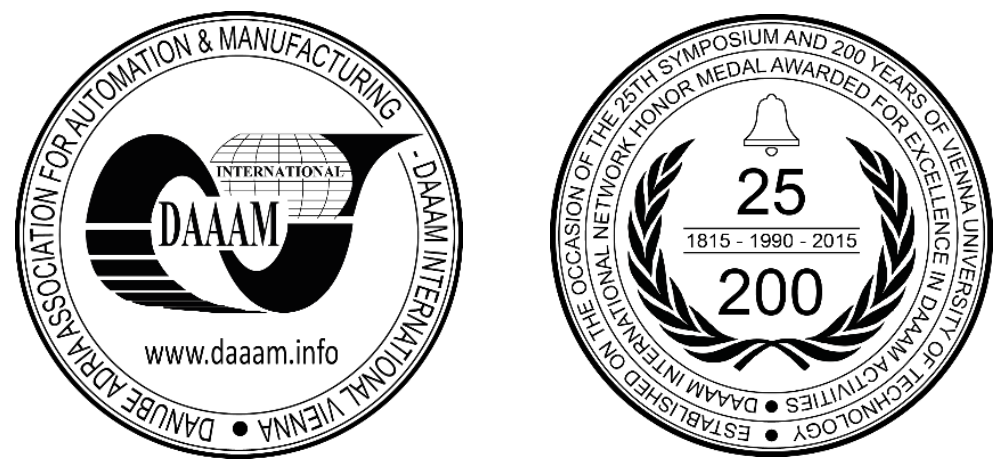

This Publication has to be referred as: Raz, K[arel]; Zahalka, M[artin] \& Chval, Z[denek] (2016). Reduction of Pantograph Influence on Energy Consumption, Proceedings of the 27th DAAAM International Symposium, pp.03580362, B. Katalinic (Ed.), Published by DAAAM International, ISBN 978-3-902734-08-2, ISSN 1726-9679, Vienna, Austria

DOI: $10.2507 / 27$ th.daaam.proceedings.053

\begin{abstract}
This article deals with energy consumption in train industry. It is specially focused on pantographs mounted on top of train. Simulations of commonly used pantograph were performed during research in order to obtain resistance (drag force). Than was created design of two different modifications in order to improve air flow around pantograph. Simulation of pantograph with additional ramp and pantograph with basement mounted in hole on train's roof was performed. This results were compared with default design in terms of drag forces and uniformity of flow. For simulation were used modern CFD (computational fluid dynamics) solvers and postprocessor. Results can be applied on different design of pantograph or on pantograph in different position. Results shows how important, comparing to whole train, is during movement energy consumption of pantograph.
\end{abstract}

Keywords: flow simulation; pantograph; train; drag force; speed.

\section{Introduction}

Pantograph is a device that is mounted on the train's roof and it is used to collect the energy from the catenary. This electrical energy is than used for train movement. The human being always needed to move from one place to another, is it about move some quantity of objects or materials, or to move himself, and the way it has been done is evolving all the time.

This energy must come from somewhere, and need to be collect it. The most common to do that is a combination of pantograph-catenary. All producers of trains are using different designs and positions of pantograph. Our aim is to get simple answer, what is more suitable.

Aerodynamic resistance of all parts has to be decreased for lower energy consumption. Our research is focused on body of pantograph. Resistance, which is main evaluating criterion, can be called as a drag force. This force is highly speed-dependent (it is on second power, obvious from (1)).

For simulation was used CFD module of advanced solver NX Nastran. Pre-processing of this task was done in software Siemens NX 10. Beginning of this kind of simulations is preparation of simulation model. This procedure is simply described on Fig.1. Parts, which are small are during this process neglected. Than is this simulation model subtracted from the volume of air and is created fine FEM mesh. 
It is necessary to use special approach called BLM (boundary layer mesh) to ensure sufficient number of elements at the surface of moving body. During our simulations was considered constant movement of train with speed $100 \mathrm{~km} / \mathrm{h}$. From definition of aerodynamic force is obvious, that higher speed results in higher energy consumption (1).

$$
\mathrm{F}=\frac{1}{2} \rho v^{2} c A
$$

Where: F...Aerodynamic force

$\rho$... Fluid viscosity

v... Velocity of the body

c... Aerodynamic coefficient

A... Transversal area of the body

For simulation was used the most common design of pantograph. Results from this simulation can be used on different design with respect to their geometry.

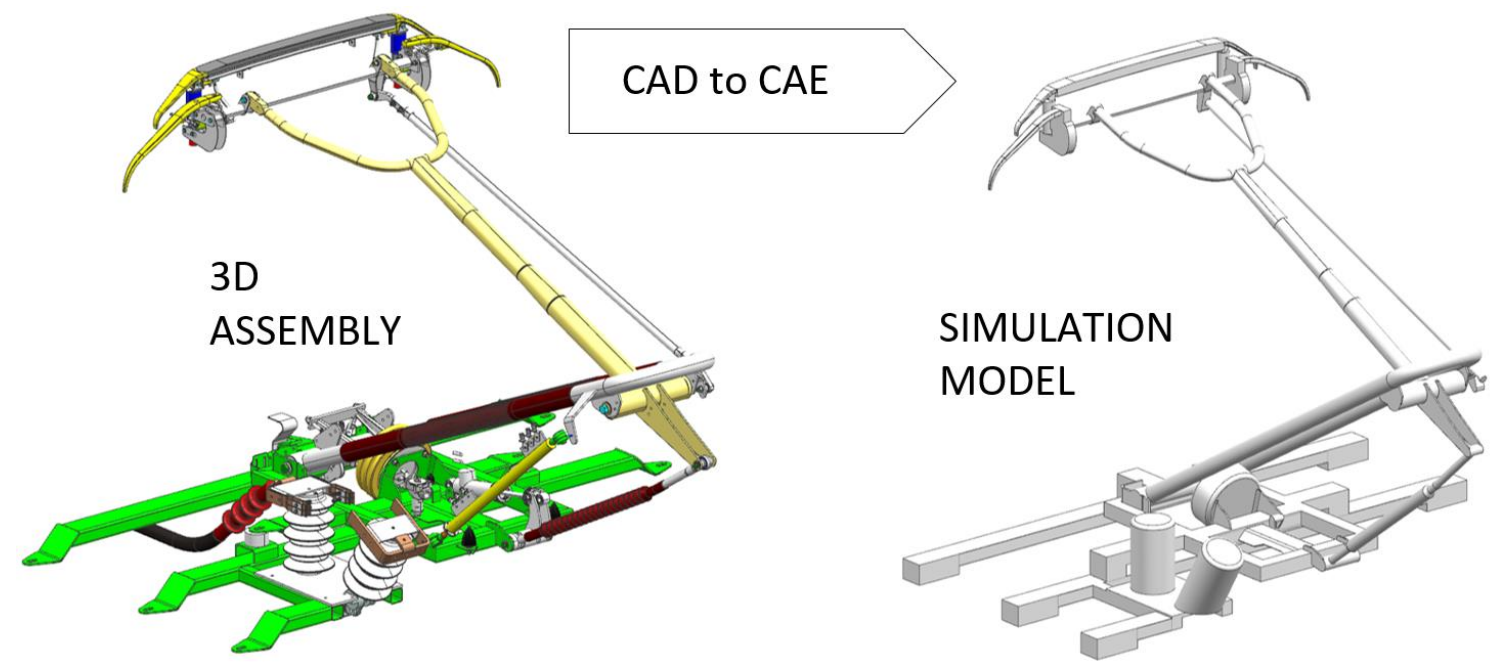

Fig. 1. Initial and simulation model of pantograph

\section{Comparing of Variants}

Detailed design of pantograph was considered for simulation from computational point of view, but train body was modelled as simplified. Additional devices mounted on top of train were neglected. Reason is because all producers are designing and mounting these devices (such as horns, electric connections...) in different positions. $[1,2,3]$

During CFD analysis were compared three designs:

- Default design without any change of geometry

- Design with added geometry of ramp in front of pantograph

- Design with change of connection between train and pantograph

Comparing was performed at two different levels. Drag force caused on pantograph body was compared during first step and then was compared uniformity of air flow around pantograph. Simply, it is possible to say that the more uniform flow is, the more suitable is for train. Uniform flow leads also to minimization of vibrations and possible mechanical defects.

For simulation was used mathematical model of flow called SST- Shear Stress Transport. It is combination of KEpsilon and K-Omega models. Far from walls, the SST — Shear Stress Transport model behaves like the K-Epsilon model. Near the walls, the SST — Shear Stress Transport model behaves like a K-Omega model. The SST — Shear Stress Transport model displays better performance for unconfined flows and flows with strong adverse pressure gradients. $[4,5,9]$

Boundary conditions were same for all simulations, and are described as:

- Input velocity of $100 \mathrm{~km} / \mathrm{h}$

- Pressure of $0.101325 \mathrm{MPa}$

- Gravity of $9.81 \mathrm{~m} / \mathrm{s}^{2}$

- Boundary layer mesh with approximately 2 million elements 


\subsection{Default Design}

Default design is obvious in Fig. 2. From CFD simulation is on the same picture clearly to see blue area behind pantograph. This area has lower speed of air flow comparing to the rest. Main aim of optimization should be decreasing of this blue area and trying to get in most places the same speed of flow [6,7]. Default design causes resistance force $442,46 \mathrm{~N}$.
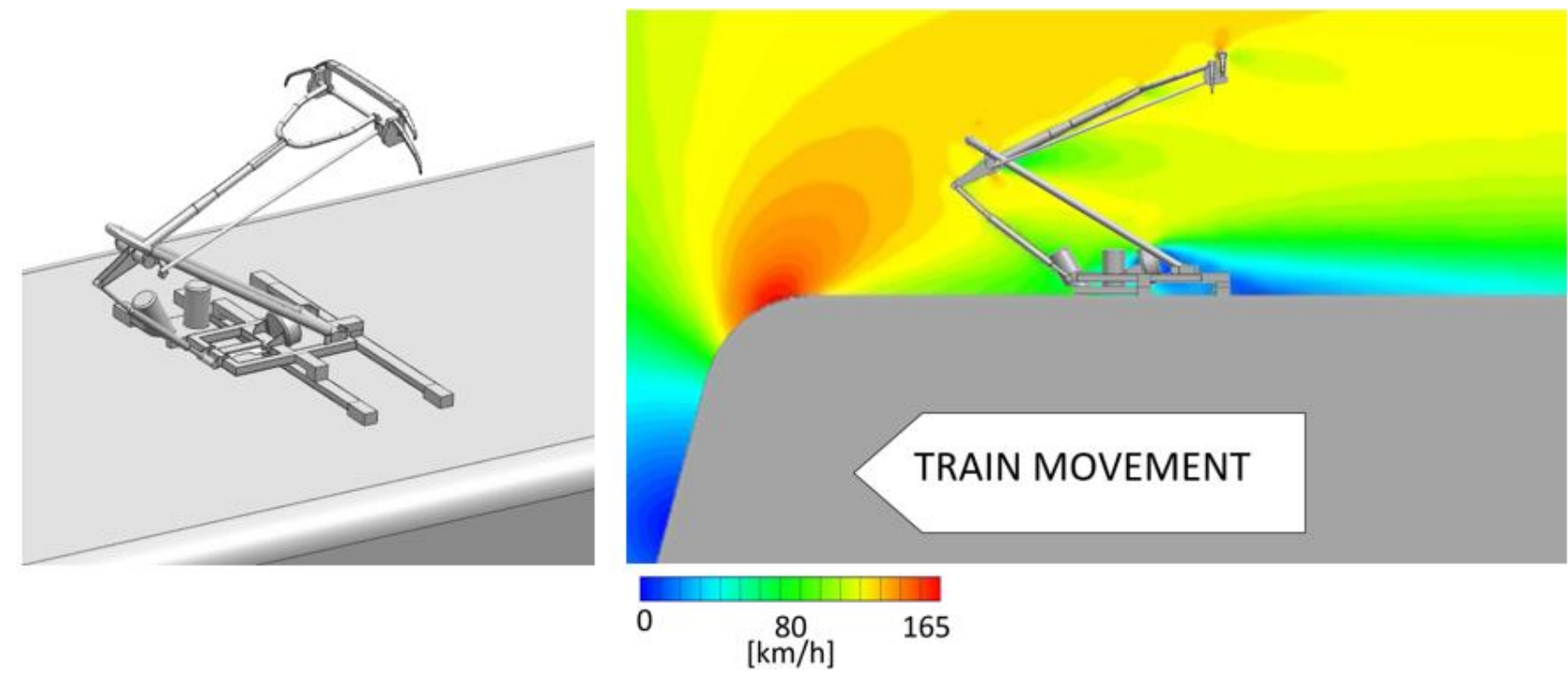

Fig. 2. Air flow around default position

\subsection{Design with added geometry of ramp in front of pantograph}

Our first try was a small ramp, trying to force the air flow go through up to the base. This concept was designed with the objective to be simple, and from this getting next improvement. In following picture is obvious zone behind the pantograph with slower air flow (Compared to default on Fig.2). This area with lower speed is bigger than in default design. It is resulting in increasing of the drag force and from this point of view is not suitable of using during real traffic. Increasing of resistance force was on level 484,19 N.
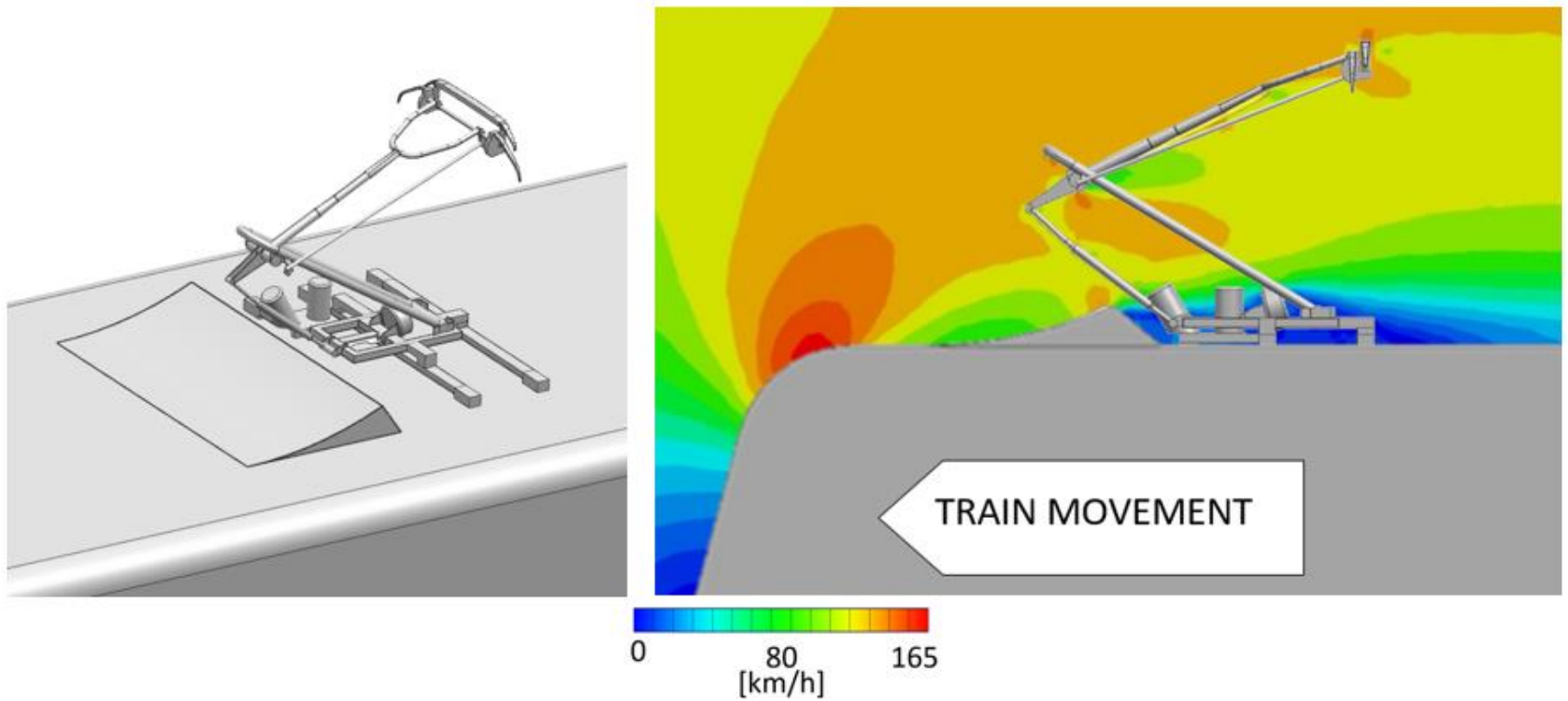

Fig. 3. Air flow around pantograph with added device 


\subsection{Design with change of connection between train and pantograph}

After we have analysed the previous results, we tried to put the pantograph in a lower position on the train's roof. In this configuration, basement of pantograph is attached to a hole on roof. It helps to flow make it more uniform. Nowadays should be approach to put all parts which are not necessary exposed to air flow inside to the train body. Main structure of train is among all producers designed to be aerodynamic and all parts connected from the outside to this body are increasing consumption of energy [8].

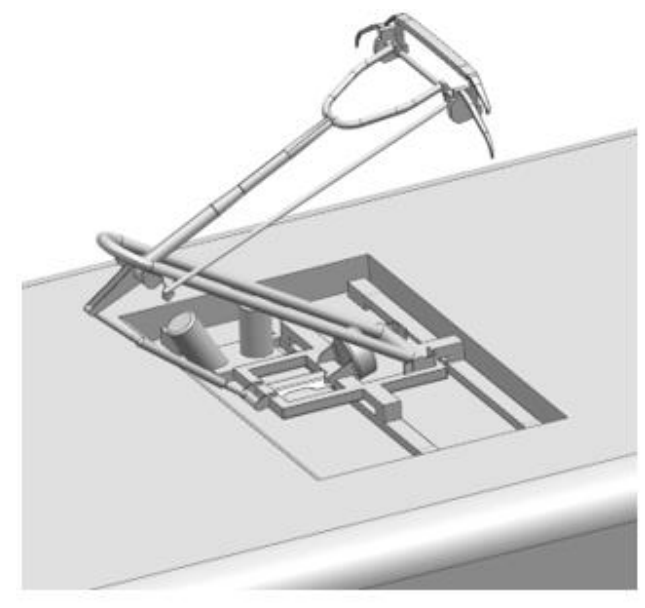

$$
\text { : }
$$

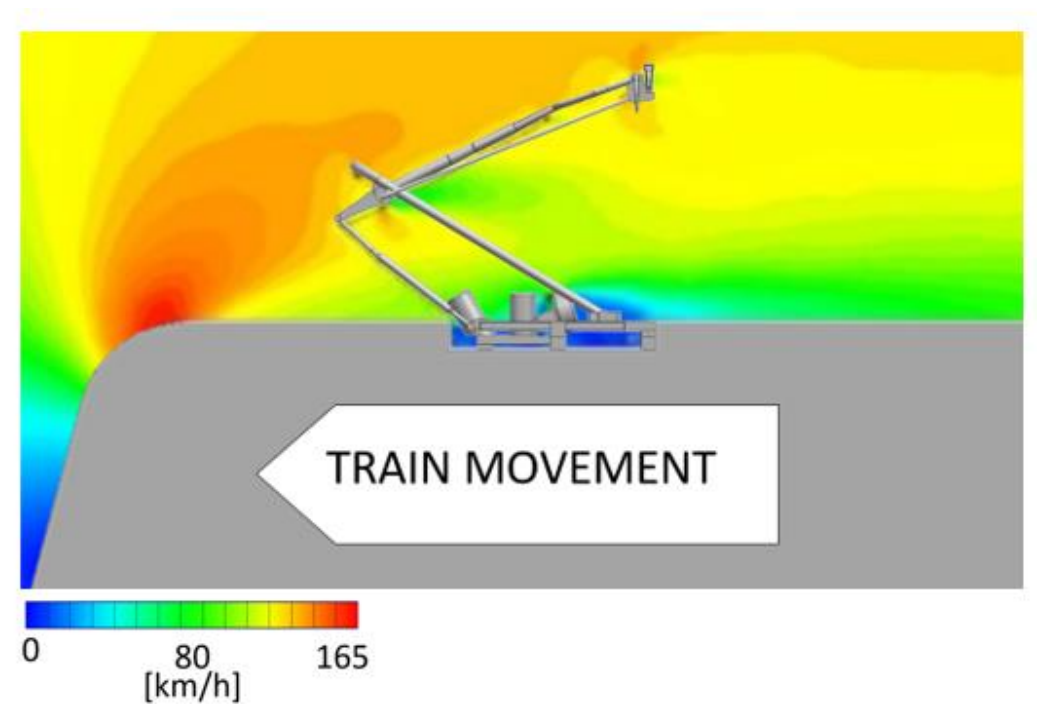

Fig. 4. Air flow around pantograph with improved basement mounted inside roof

This design results in decreasing of resistance force on final level $369,85 \mathrm{~N}$. Uniformity of air flow is visible from Fig.4. Blue area behind pantograph is significantly smaller comparing previous designs. This design results in some vorticities. They are visible on Fig.5. There are some streamlines around body of train and pantograph. In hole below pantograph are visible some vortexes which are caused by this design.

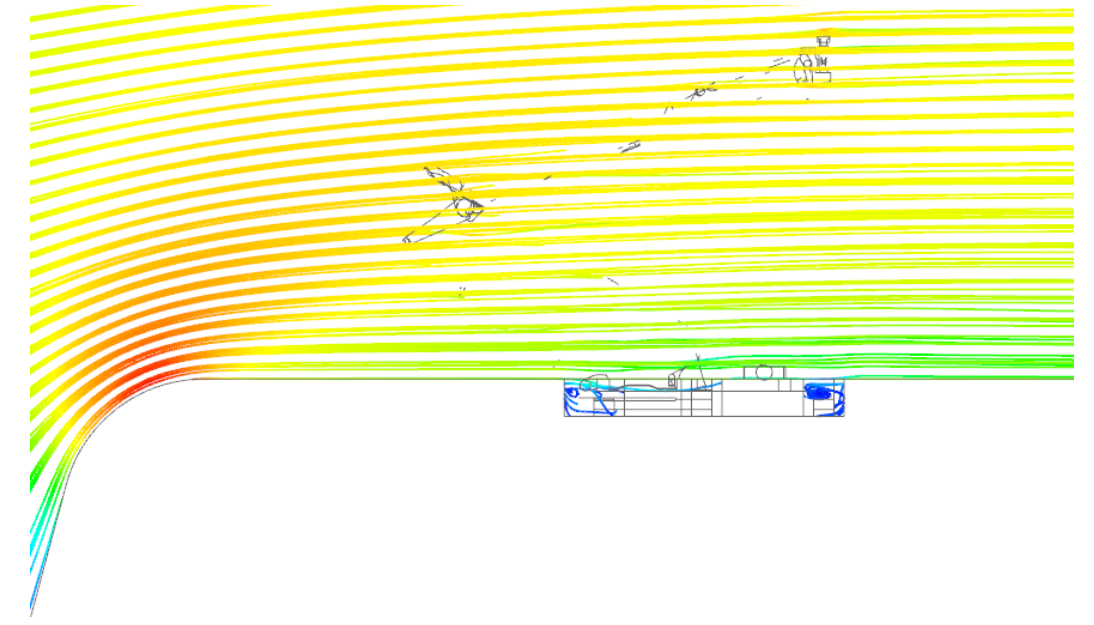

Fig. 5. Streamlines around pantograph and train

\section{Conclusion}

Results are described in following table. Significant is difference comparing to default design. Is obvious, that adding additional ramp is not resulting in improvement and has negative influence. Good approach is hiding some parts (basement) of pantograph under level of roof. This leads to decreasing of drag force (it means resistance force) by $16 \%$. For clear understanding is added also lift force of each design. This force is acting in vertical direction and is $10 \%$ of drag force. Because of that was for comparing used only drag force. 


\begin{tabular}{|c|c|c|c|}
\hline & Lift (N) & $\begin{array}{c}\text { Drag } \\
(\mathbf{N})\end{array}$ & $\begin{array}{c}\text { Drag } \\
\text { Difference }\end{array}$ \\
\hline Default design & 49 & 442,46 & $0 \%$ \\
\hline Design with ramp in front of pantograph & 35,4 & 484,19 & $9 \%$ \\
\hline Design with change of connection between train and pantograph & 25,36 & 369,85 & $-16 \%$ \\
\hline
\end{tabular}

Table 1. Results summary

Before the conclusion, we must be warned that a lot of parts weren't take in account during the simulations (can create interference in the flow nearby the surface) and the pantograph's height can variate during the travel. In these simulations were used the average height, and the higher the pantograph is, the greater the force acting on it. It is caused by the transversal area changes (1).

Further steps should be simulation of air flow inside air tunnel and validating of previous simulations. This is possible to done by comparing streamlines from virtual (CFD) simulations and from real experiment in tunnel.

Nowadays should all products be designed with respect to energy consumption and its minimization. Our research shows, that all parts (even the smaller ones) have influences and it is necessary to optimize them in order to get final products with better properties.

\section{Acknowledgments}

The article has been prepared under project LO1502 'Development of the Regional Technological Institute' under the auspices of the National Sustainability Programme I of the Ministry of Education of the Czech Republic aimed to support research, experimental development and innovation.

\section{References}

[1] Ambrósio, J., Pombo, J. (2012). A computational procedure for the dynamic analysis of the catenary-pantograph interaction in high-speed trains, ISSN 1429-2955, Journal of Theoretical and Applied Mechanics, pp. 681-699

[2] Wang, Y., Liu, Z.-G., Huang, K., Gao, S.-B. (2014). Pantograph-catenary surface heat flow analysis and calculations based on mechanical and electrical characteristics , Journal of the China Railway Society, ISSN 10018360 pp. 36-43

[3] Bautista, A., Montesinos, J., Pintado, P. (2016). Dynamic interaction between pantograph and rigid overhead lines using a coupled FEM - Multibody procedure, Mechanism and Machine Theory, pp. 100-111, doi:10.1016/j.mechmachtheory.2015.10.009

[4] Arsene, S., Sebesan, I., Popa, G. (2015). The Influence of Wind on the Pantograph Placed on the Railway Electric Vehicles Bodywork, Proceedings of 5th World Conference on Learning, Teaching and Educational Leadership, pp. 1087-1094, doi:10.1016/j.sbspro.2015.04.185

[5] Popa, C. L.; Parpala, R. C. \& Cotet, C. E.(2012). Contact Identification for Assembly/Disassembly Process in CADCAE Software, Annals of DAAAM for 2012 \& Proceedings of the 23rd International DAAAM Symposium, ISBN 978-3-901509-91-9, ISSN 2304-1382, pp 0613 - 0616, Editor B[ranko] Katalinic, Published by DAAAM International, Vienna, Austria

[6] Ahmed, H. \& Chacko, S.(2012). Computational Optimization of Vehicle Aerodynamics, Annals of DAAAM for 2012 \& Proceedings of the 23rd International DAAAM Symposium, ISBN 978-3-901509-91-9, ISSN 2304-1382, pp 0313 - 0318, Editor B[ranko] Katalinic, Published by DAAAM International, Vienna, Austria

[7] Ramaj, V.; Dhori, A.; Ramaj, V.; Dhoska, K.; Koleci, A. \& Konjusha, E. (2010). CFD Code Turbulence Models Validation for Turbulent Flows Over a Wavy Surface, Annals of DAAAM for 2010 \& Proceedings of the 21st International DAAAM Symposium, 20-23rd October 2010, Zadar, Croatia, ISSN 1726-9679, ISBN 978-3-90150973-5, Katalinic, B. (Ed.), pp. 0425-0426, Published by DAAAM International Vienna, Vienna

[8] Chwastyk, P. \& Kolosowski, M.(2012). Integration CAD/CAPP/CAM Systems in Design Process of Innovative Products, Annals of DAAAM for 2012 \& Proceedings of the 23rd International DAAAM Symposium, ISBN 9783-901509-91-9, ISSN 2304-1382, pp 0397 - 0400, Editor B[ranko] Katalinic, Published by DAAAM International, Vienna, Austria

[9] Piscan, I.; Janssens, T. \& Predincea, N. (2011). Experimental Validation of FEM for Frictional Contacts, Annals of DAAAM for 2011 \& Proceedings of the 22nd International DAAAM Symposium, 23-26th November 2011, Vienna, Austria, Volume 22, No. 1, ISSN 1726-9679, ISBN 978-3-901509-83-4, Katalinic, B. (Ed.), pp. 0741-0742, Published by DAAAM International Vienna, Vienna 